\title{
Carbon nanotubes-properties and applications: a review
}

\author{
Khalid Saeed Ibrahim* \\ Department of Chemistry, University of Malakand, Khyber Pakhtunkhwa, Pakistan
}

\section{Article Info}

Received 2 May 2013

Accepted 12 July 2013

*Corresponding Author

E-mail: Khalidkhali12002@yahoo.com

\section{Open Access}

DOI: http://dx.doi.org/

10.5714/CL.2013.14.3.131

This is an Open Access article distributed under the terms of the Creative Commons Attribution Non-Commercial License (http://creativecommons.org/licenses/ by-nc/3.0/) which permits unrestricted non-commercial use, distribution, and reproduction in any medium, provided the original work is properly cited.

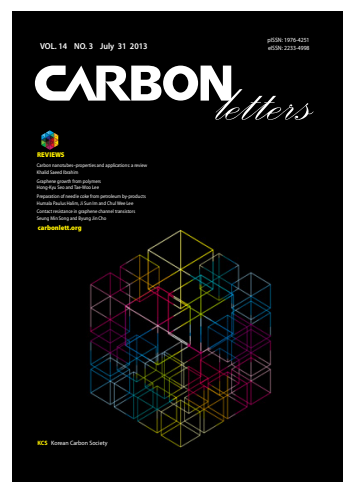

http://carbonlett.org

pISSN: 1976-4251

elSSN: 2233-4998

Copyright $\odot$ Korean Carbon Society

\begin{abstract}
The carbon nanotube (CNT) represents one of the most unique inventions in the field of nanotechnology. CNTs have been studied closely over the last two decades by many researchers around the world due to their great potential in different fields. CNTs are rolled graphene with $\mathrm{SP}^{2}$ hybridization. The important aspects of CNTs are their light weight, small size with a high aspect ratio, good tensile strength, and good conducting characteristics, which make them useful as fillers in different materials such as polymers, metallic surfaces and ceramics. CNTs also have potential applications in the field of nanotechnology, nanomedicine, transistors, actuators, sensors, membranes, and capacitors. There are various techniques which can be used for the synthesis of CNTs. These include the arc-discharge method, chemical vaporize deposition (CVD), the laser ablation method, and the sol gel method. CNTs can be single-walled, double-walled and multi-walled. CNTs have unique mechanical, electrical and optical properties, all of which have been extensively studied. The present review is focused on the synthesis, functionalization, properties and applications of CNTs. The toxic effect of CNTs is also presented in a summarized form.
\end{abstract}

Key words: carbon nanotube, synthesis, functionalization, toxic effect of CNTs

\section{Introduction}

In recent years, much research has focused on nanotechnology and nanocomposites. Researchers select specific filler and introduce it into a specific polymer to achieve a specific composite with modified properties. If the filler is a nano material, the composite is termed a nanocomposite [1]. Nanotechnology brings evolutionary changes to everyday life.

\subsection{Nanotechnology}

The word "nano" is from the Greek, meaning dwarf (small); scientific treatment at the nano level (atomic level) with the help of special scientific instruments is known as nanotechnology, which has become a well-known field in the last three decades [2]. The word "nanotechnology" was coined by Norio Taniguchi in 1974, in Japan. He stated that, "nanotechnology mainly consists of the processing steps of the separation, consolidation and deformation of materials by one atom or one molecule [3]. Nanotechnology is a vast field which explores many facts about the structures and properties of materials.

\subsection{Carbon nanotubes (CNTs)}

CNTs, also called buckytubes, are cylindrical carbon molecules with unique properties that make them potentially useful in a wide variety of applications. These include applications in nano-electronics, optics, and materials applications. CNTs exhibit extraordinary strength as well as unique electrical, mechanical and thermal properties. CNTs are the members of the fullerene family, which was discovered by Kroto et al. [4] in 1985. Buckyballs are spherical fullerenes, whereas CNTs are cylindrical, with at least one end typically capped with a 


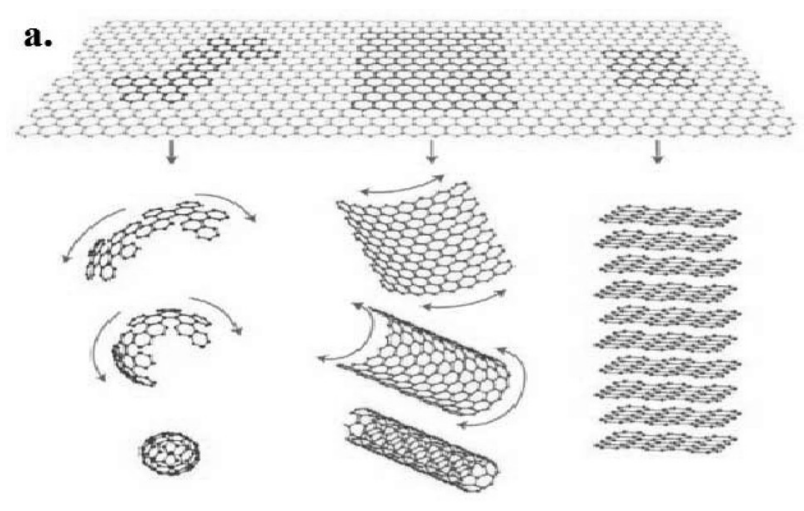

b.
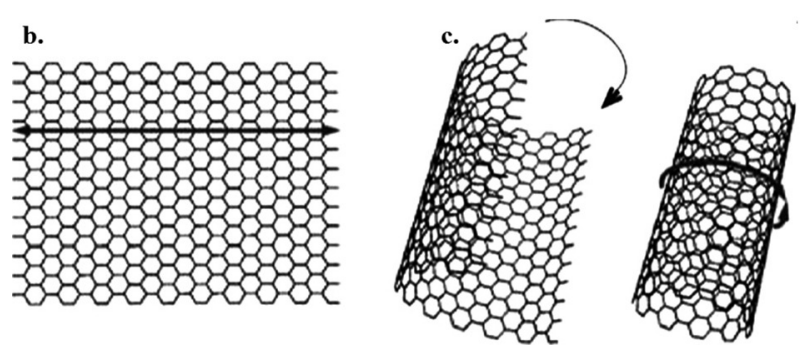

Fig. 1. (a) Formation of graphene derivatives. (b) Graphene sheet. (c) Graphene sheets rolled into carbon nanotubes. Reprinted from Geim and Novoselov [9] with permission from Nature Publishing Group and Shabnam et al. [10] with permission from Elsevier.

hemisphere with the buckyball structure. The name CNT derives from the size, as the diameter of a nanotube is on the order of a few nanometers. Iijima [5] first synthesized multi-walled carbon nanotubes (MWNTs) in 1991 using a simple arc-evaporation method. However, CNTs were discovered long before researchers even imagined that carbon may exist in such a diverse allotropic form. In 1952, Radushkevich and Lukyanovich [6] reported the discovery of "worm-like" carbon formations. These were observed during their study of the soot formed by the decomposition of carbon monoxide (CO) on iron particles at $600^{\circ} \mathrm{C}$. On the basis of many experiments and transmission electron microscope (TEM) images and other characterization techniques, the authors concluded that the formed product consisted of long filamentary or needle-like carbon crystals with diameters of about $50 \mathrm{~nm}$. The discovery of nanotubes passed almost unnoticed due to lack of attention to the field of nanotechnology at that time, like a number of other areas before and after [7].

\subsection{Structure of CNTs}

CNTs, also known as tubular fullerenes, are cylindrical graphene sheets of $\mathrm{sp}^{2}$-bonded carbon atoms. In CNTs the graphene sheet is rolled upon itself to form different allotropes of carbon, including graphite, fullerenes and CNTs [8].

\subsection{Types of CNTs}

CNTs can be divided into three categories on the basis of the number of tubes present in the CNTs. These are described below.

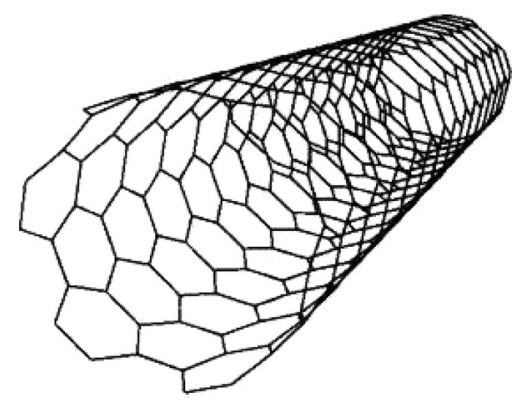

Fig. 2. Single-walled carbon nanotubes, surface and internal view. Reprinted from Saether et al. [11] permission from Elsevier.

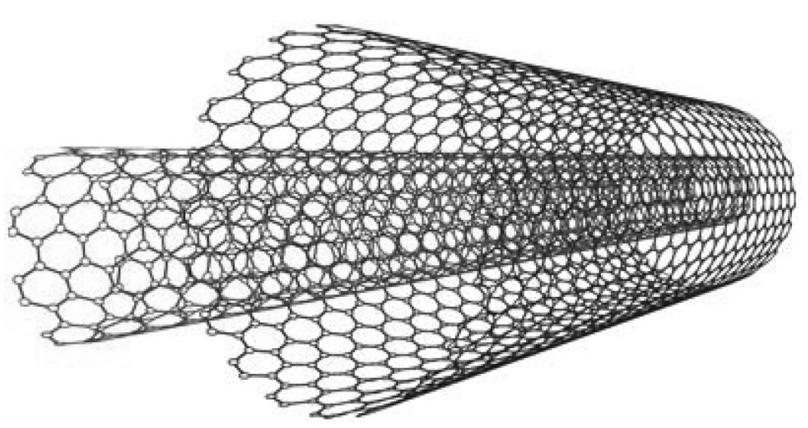

Fig. 3. Double-walled carbon nanotubes. Reprinted from Pichler [12] with permission from Nature Publishing Group.

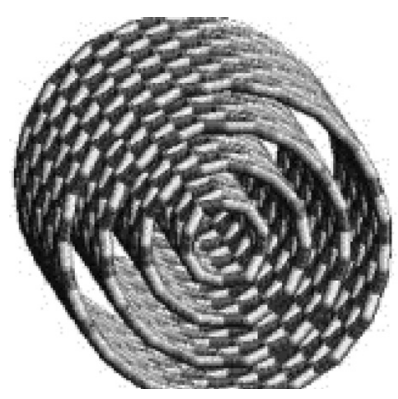

Fig. 4. Multi-walled carbon nanotubes. Reprinted from Dresselhaus et al. [14] with permission from Elsevier.

\subsubsection{Single-walled CNTs}

Single-walled CNTs (SWCNTs) are made of a single graphene sheet rolled upon itself with a diameter of 1-2 nm (Fig. 2). The length can vary depending on the preparation methods.

\subsubsection{Double-walled CNTs}

These nanotubes are made of two concentric carbon nanotubes in which the outer tube encloses the inner tube, as shown in Fig. 3.

\subsubsection{Multi-walled CNTs}

MWNTs consist of multiple layers of graphene rolled upon itself with diameters ranging from 2 to $50 \mathrm{~nm}$ depending on the number of graphene tubes. These tubes have an approximate inter-layer distance of $0.34 \mathrm{~nm}$ [13]. 


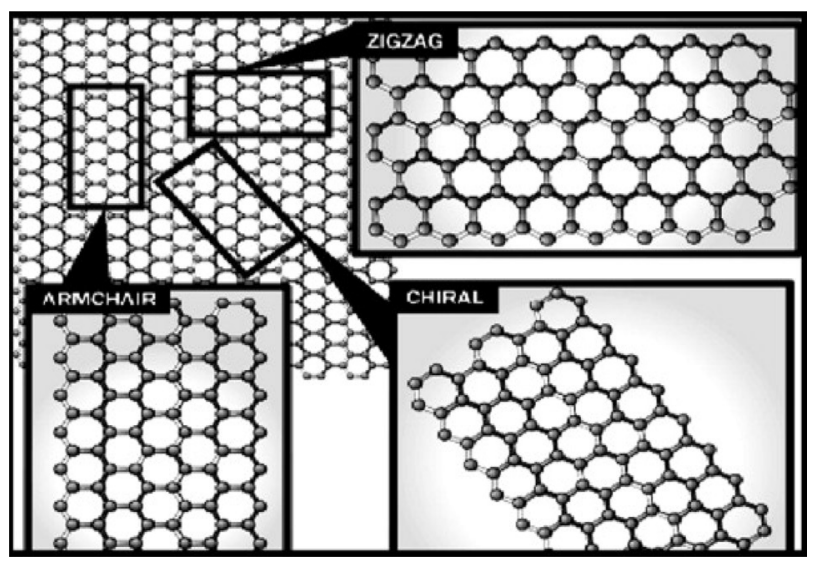

Fig. 5. Different types of carbon nanotubes on the basis of chirality. Ahmad et al. [16] with permission from Elsevier.

\subsubsection{Types on the basis of chirality}

Chirality is a very important factor in determining the electrical properties of CNTs. On the basis of chirality, there are three types of CNTs, i.e., chiral, armchair, and zigzag [15]. These three types are shown in Fig. 5.

\section{Synthesis of CNTs}

CNTs can be prepared by various methods, such as the arcdischarge method, chemical vapor deposition (CVD), and laser ablation.

\subsection{Arc-discharge method}

In 1991, Iijima [5] reported the existence of a new tabularshaped species, now called CNTs. The tubes were produced using an arc-discharge evaporation method similar to that used for fullerene synthesis in the past. Carbon needles with diameters ranging from 4 to $30 \mathrm{~nm}$ and lengths up to $1 \mathrm{~mm}$ were grown on the negative end (cathode) of a carbon electrode by means of the direct current (DC) arc-discharge evaporation of carbon in an argon-filled vessel (100 torr). Ebbesen and Ajayan [17] reported the large-scale synthesis of MWNTs by this method.

The arc-discharge assembly includes two vertical thin electrodes installed in the center of the chamber. The lower electrode (cathode) has a shallow dip to hold a small piece of iron during the evaporation phase. The arc-discharge $\mathrm{c}$ a $n$ be generated by running a DC current of $200 \mathrm{~A}$ at 20 $\mathrm{V}$ between the two electrodes. The use of the three components, argon, iron and methane, is critical for the synthesis of SWNTs. In the arc-discharge synthesis of nanotubes, Bethune et al. [18] used as anodes thin electrodes with bored holes which were filled with a mixture of pure powdered metals $(\mathrm{Fe}, \mathrm{Ni}$ or $\mathrm{Co}$ ) and graphite. The electrodes were vaporized with a relatively low current of 95-105 A at 100 500 Torr in a He atmosphere. Large quantities of CNTs were generated using this technique by Journet et al. [19]. The arc was generated between two graphite electrodes in a reactor under a helium atmosphere (660 mbar).

\subsection{Laser ablation}

In 1996, Thess et al. [20] reduced high yields $(>70 \%)$ of CNTs by means of the laser ablation of graphite rods with small amounts of $\mathrm{Ni}$ and $\mathrm{Co}$ at $1,200^{\circ} \mathrm{C}$.

In this method, the graphite target is bombarded with laser light. The tube grows until too many catalyst atoms aggregate on the end of the nanotube. The large particles either detach or become over-coated with sufficient amounts of carbon to poison the catalysis. This allows the tube to terminate with a fullerenelike tip or with a catalyst particle.

\subsection{Chemical vapor deposition}

In the above synthetic techniques, two major problems remain, i.e., the realization of both large-scale production and ordered synthesis [21]. However, in 1996, a CVD was discovered for nanotube synthesis [22,23]. This method is capable of controlling the growth direction on the substrate and synthesizing a large quantity of nanotubes [22]. During this process, a mixture of hydrocarbon gas, acetylene, methane or ethylene and nitrogen is introduced into the reaction chamber. During the reaction, nanotubes are formed on the substrate by the decomposition of the hydrocarbon at temperatures $700^{\circ} \mathrm{C}-$ $900^{\circ} \mathrm{C}$ at atmospheric pressure [23]. This technique has two major benefits. The nanotubes are obtained at a much lower temperature, although at a lower quality, and the catalyst can be deposited over the substrate, which allows CNTs to adopt well-organized structures.

\subsection{Vapor-phase growth}

This is a relatively new technique and a modified form of CVD. The main difference is that the CNTs are synthesized directly from the reaction gas and catalytic metal in the chamber without a substrate [24]. Two furnaces are placed inside the reaction chamber. The catalyst used in this case is ferrocene. Vaporization of catalytic carbon is maintained at a relatively low temperature in the first furnace. Fine catalytic particles are formed here and when they reach the second furnace, and the decomposed carbons are absorbed in this catalyst by diffusion, where they are converted into CNTs.

\subsection{Flame synthesis method}

Another method by which CNTs can be prepared is the flame synthesis method. In this method, hydrocarbon flames are utilized. These flames assist with the initiation and growth of CNTs. Gases such as $\mathrm{CO}, \mathrm{CH}_{4}, \mathrm{C}_{2} \mathrm{H}_{2}, \mathrm{C}_{2} \mathrm{H}_{4}$, and $\mathrm{C}_{2} \mathrm{H}_{6}$, which are present in the post-flame area, are rich sources of carbon. The reaction is exothermic and chemical energy released in the form of heat in the flame supports endothermic carbon deposition reactions. Catalysts are also required to provide reaction sites for the deposition of solid black carbon. CNTs grow in the same manner as in CVD. If an appropriate catalyst and flame and reaction conditions are provided, large amounts of CNTs can be gained commercially [25]. 


\subsection{Recent trends in the synthesis of CNTs}

A recent nebulized spray pyrolysis method has also been used for the synthesis of MWNTs. A nebulized spray, the key factor in this method, is generated by a special ultrasonic atomizer. MWNTs with fairly uniform diameters in aligned bundles have been obtained via this technique. Using an ultrasonic nebulizer, ferrocene (catalyst) and ethanol (as solvent and carbon source) are sprayed into a tubular furnace at a fixed temperature of $800^{\circ} \mathrm{C}$ under an argon flow of $1 \mathrm{~L} / \mathrm{min}$. Ethanol is used as a solvent as well as a carbon source due to its non-polluting nature, low cost, harmless byproducts (e.g., CO), and ease of handling. High growth of MWNTs on a surface can be produced. The advantage of using a nebulized spray is the ease of scaling into an industrial-scale process, as the reactants are fed into the furnace continuously [26].

\section{Properties}

CNTs reportedly have extremely high surface areas, large aspect ratios, and remarkably high mechanical strength. The tensile strength of CNTs is 100 times greater than that of steel, and the electrical and thermal conductivities approach those of copper $[27,28]$. These unique properties make CNTs good candidates as fillers in different polymers and ceramics to realize desirable consumer products $[29,30]$. It has also been predicted that CNT-based field-effect transistors (FETs) will soon supplant their silicon-based analog counterparts [31]. CNTs are also good incorporating agents due to their unique electrical, mechanical and thermal properties.

\subsection{Electronic nature of CNTs}

CNTs show electrical properties in chiral forms. Researchers have demonstrated that CNTs exhibit unique conductive properties. These results were the first to suggest that geometric differences such as defects, chirality, different diameters and the degree of crystallinity of the tubular structure greatly influence the electronic properties of CNTs $[32,33]$. SWNTs are metals with resistivities that range from $0.34 \times 10^{-4}$ to $1.0 \times 10^{-4} \mathrm{ohm} \cdot \mathrm{cm}$ [27]. Considering the bonding of the carbon atoms in CNTs, arranged in a hexagonal lattice, each carbon atom is covalently bonded to three neighbor carbons via $\mathrm{sp}^{2}$ molecular orbitals. Thus, the fourth valence electron remains free in each unit, and these free electrons are delocalized over all atoms and contribute to the electrical nature of CNTs. Thus, CNTs can be conducting or semi-conducting types depending on the type of chirality [2537] Semiconducting SWNTs are usually in the form of p-type semiconductors [38]. MWNTs are composed of many tubes of SWNTs and therefore are not likely to be strictly one-dimensional conductors. A pseudo-gap was observed in $I-V$ measurements, which attributes to its conducting nature [39].

From the above discussion, we note that the electrical properties of both SWNTs and MWNTs have been relatively well explored. This area has been a field of great interest since the last decade $[40,41]$. SWNTs, due to the ballistic nature of electron transport, can be described as quantum wires. On the other hand, transport in MWNTs is found to be fairly diffusive or quasi-ballistic [42]. CNTs, due to their electronic nature, can be used in transistors and other switching applications in advanced electronics [43]. The most recent application of nanotubes was as an emitter. The important aspect of CNT emitters is that the emission can be obtained at a lower threshold voltage [44]. CNTs can also be used in sensors, micron-scale on-chip triodes at a high frequency $(>200 \mathrm{MHz})$, vacuum microelectronics, and for X-ray generation $[45,46]$.

\subsection{Mechanical properties of CNTs}

CNTs are considering as the strongest materials in nature at this point. The literature suggests that CNTs are very strong materials, especially in the axial direction [47]. The Young's modulus ranges from 270 to $950 \mathrm{GPa}$, while the tensile strength is also very high, in the range of 11-63 GPa. Several reports have shown that in the radial direction, $\mathrm{CNTs}$ are rather soft [48]. The first TEM observation of radial elasticity showed that Vander Waal's forces can deform two adjacent nanotubes [49]. Later, nano-indentations with an atomic force microscope (AFM) were performed by different groups of researchers to measure the radial elasticity of MWNTs quantitatively, and tapping/contact mode AFM was recently used to examine SWNTs [50-52]. The results showed that CNTs are in fact very soft in the radial direction. The radial direction elasticity of CNTs is important, especially for the formation of CNT nanocomposites and their mechanical properties, in which embedded tubes are subjected to large deformation in the transverse direction when a load is applied to a composite structure. Because the carboncarbon bonds observed in graphite are among the strongest in nature, CNTs have excellent potential as they are the stiffest and toughest structure ever synthesized by scientists. Studying CNTs under TEM has shown that these materials are flexible and do not break upon bending [53-57]. Earlier theoretical calculations were carried out to predict the mechanical properties of CNTs [58-60]. The first attempt to determine the Young's modulus for individual MWNTs was performed by Treacy et al. [28], who measured the amplitudes of thermal vibrations in CNTs under TEM. They demonstrated that nanotubes possess an average Young's modulus of $\mathrm{Y}=1-1.8 \mathrm{TPa}$, which is extremely high compared to commercially available carbon fibers ( $\mathrm{Y} \geq 800 \mathrm{GPa}$ ). Various research groups performed direct measurements of the bending forces of MWNTs as a function of the displacement inside an AFM. The values for the Young's modulus were found to be between 0.32 and $1.47 \mathrm{TPa}$ [6170]. Falvo et al. [61] observed that MWNTs could be bent at sharp angles without undergoing any structural fracturing using an AFM tip. Endo et al. [62] observed that while breaking vapor-grown CNTs in liquid nitrogen, an inner tubule could survive this pressure. Zhu et al. [63] applied high pressures (50 $\mathrm{GPa}$ ) at room temperature, using shock waves, to arc-discharge MWNTs and noted that the tubes do not break but collapse; that is, the outer shells transform into curled graphene domains while the inner cores display structural defects. More theoretical work on the mechanical properties of CNTs was carried out by Sinnot et al. [70], who found that SWNTs could exhibit a Young's modulus as high as that of diamond. Yakobson [71] and $\mathrm{Ru}$ [72] proposed a mechanism of CNT transformation under uniaxial tension, leading to pentagon-heptagon defects in 
these tubes under high stress. Guanghua et al. [73] also showed theoretically that the mechanical properties of SWNTs are mainly dependent on the diameter. They estimated the theoretical Young's modulus of nanotubes, of » $1 \mathrm{~nm}$ diameter, is in the range of 0.6-0.7 TPa. Hernandez et al. [74] also obtained theoretical values of the Young's modulus which were in close agreement with those obtained experimentally for MWNTs $(1-1.2 \mathrm{TPa})$. They also reported that the increase in diameter is proportional to the enhancement of the mechanical properties and that if the diameter is increased to a certain value, the Young`s moduli of the tubes approach those of planar graphite. Yu et al. [47,50] measured the Young's modulus of individual SWNTs, reporting values between 320 and $1470 \mathrm{GPa}$ and determining a breaking strength of SWNTs on the perimeter of each rope ranging from 13 to $52 \mathrm{GPa}$.

\subsection{Thermal properties of CNTs}

As rolled graphitic structures, CNTs are of great importance and interest not only for their electronic and mechanical properties, but also for their thermal properties. Although their size is very small, the quantum effects are important and the lowtemperature specific heat and thermal conductivity show direct evidence of the 1-D quantization of the phonon band structure in CNTs $[56,70,75]$. The incorporation of pristine and functionalized nanotubes to different materials can double the thermal conductivity for a loading of only $1 \%$, showing that nanotube composite materials may be useful for thermal management applications in industries. Kim et al. [76] measured the thermal conductivity of individual MWNTs and found it to be 3,000 $\mathrm{W} / \mathrm{K}$ (higher than that of graphite) at room temperature. Beside this they also determined that the value is two orders higher than the magnitude those obtained for bulk MWNTs. A similar study was carried for SWNTs, with this result being greater than 200 $\mathrm{W} / \mathrm{m} \mathrm{K}$ for SWNTs [77]. There are several factors which influence the thermal properties such as the number of phonon-active modes, the length of the free path for the phonons, and boundary surface scattering [77-79]. These properties also depend on the atomic arrangement, the diameter and length of the tubes, the number of structural defects and the morphology, as well as the presence of impurities in the CNTs [80-82].

\section{Dispersion of CNTs}

One of the problems associated with CNTs is the agglomeration of these tubes due to weaker intermolecular forces, leading to difficulty in their dispersion in different polymeric mediums and even in various solvents. The functionalization of CNTs is carried out to overcome their agglomeration and bundle formation, which also enhances their dispersion in polymeric materials and solvents. Thus, the purification or functionalization of CNTs is very important to enhance their degrees of reactivity and homogenous dispersion. Purification removes unwanted particles that remain after the synthesis process, while functionalization introduces a specific functional group onto the side chains or ends of the CNTs [83]. Different methods are used by researchers for the functionalization and dispersion of CNTs. These include the following:

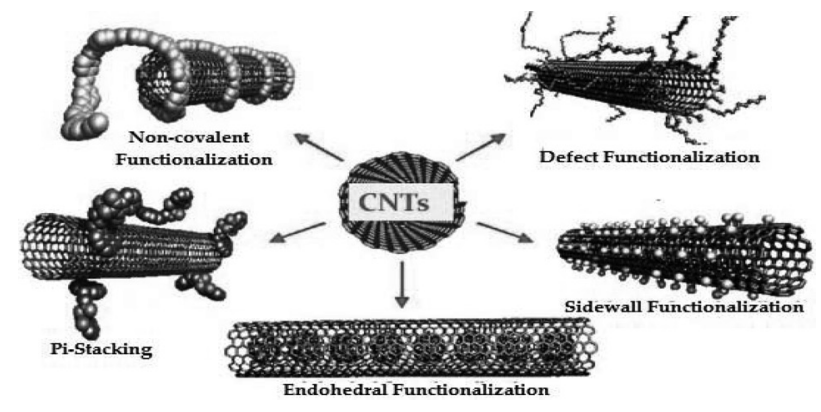

Fig. 6. Most common types of functionalization. CNT, carbon nanotube. Reprinted from Hirsch [84] with permission from Wiley-VCH Verlag GmbH.

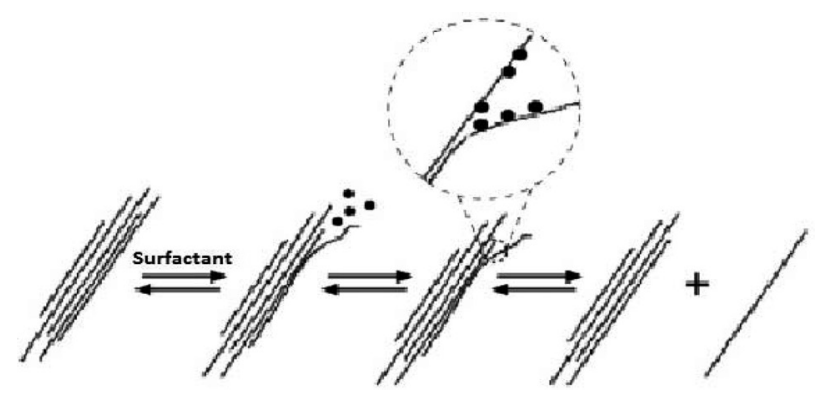

Fig. 7. Mechanism of carbon nanotube dispersion with the help of a surfactant. Reprinted from Vaisman et al. [90] with permission from Elsevier.

\subsection{Non-covalent functionalization}

This type of functionalization is based on Van der Waal's forces. Beside these forces, hydrophobic or Pi-Pi interactions have also been reported. Non-covalent functionalization is important and interesting because it does not damage or modify the CNTs structure to a great extent. In solution beside van-der Waal's forces some other forces are also involved, which render the efficiency of this type of functionalization. Some common examples of this type of functionalization include use of surfactant, especially with SWNTs, CNT wrapping, and non-covalent protein interactions [84].

\subsection{Covalent functionalization}

In this type of functionalization, the desired groups are attached onto the sidewall or tips of the CNTs permanently in an irreversible manner. Various chemical groups such as carboxylic, p-aminobenzoic acid, fluorine, added dichloro-carbon groups are attached to the surface or at the ends of the CNTs [85-88]. The advantages of chemical functionalization are that it can be attached covalently with polymeric materials and dispersed well in different solvents. The main disadvantage of the chemical function is the production of defects on CNTs. Various methods of the functionalization of CNTs are shown in Fig. 6.

\subsection{Dispersion of CNTs using surfactants}

The use of surfactants has also been reported for the purpose of CNT dispersion in polymeric materials [89]. Some important surfactants such as polyethylene glycol, sodium dodecyl 


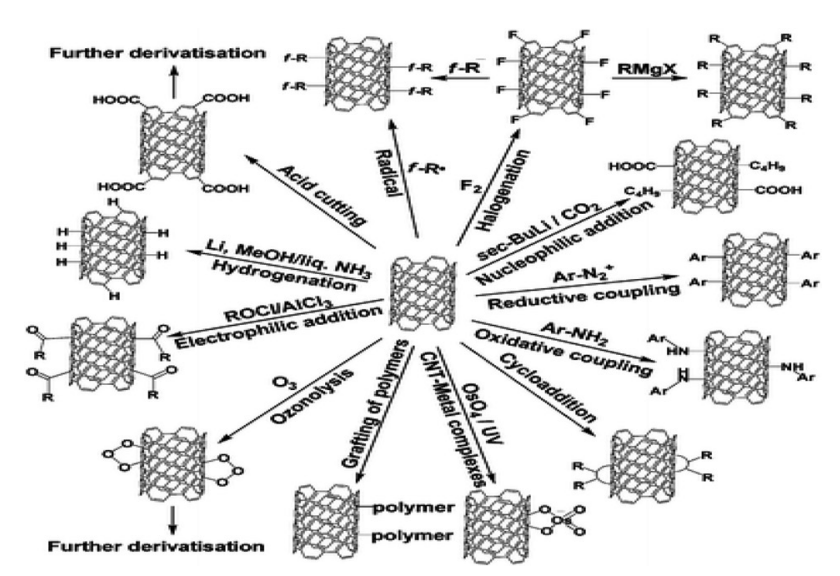

Fig. 8. Functionalization of carbon nanotubes. Reprinted from Wu et al. [87] with permission from The Royal Society of Chemistry.

sulfate, and dodecyl-benzene sodium sulfonate are commonly use for the reduction of the aggregative tendency of CNTs in water and other related solvents. It was proposed that the presence of benzene rings is responsible for the high dispersive efficiency of CNTs. The p-stacking interactions of benzene rings onto the CNT surfaces are believed to increase the adsorption ratio of surfactants. It was also determined that besides aromatic groups, naphthenic (saturated rings) groups also provide good surfactant-tube affinity. Fig. 7 show the mechanism by which the surfactant micelles overcome the weaker Van der Waal's forces.

\subsection{Physical dispersion by ultrasonication}

Physical dispersion is also an important way to decrease the agglomeration tendency of CNTs. Sonication provides certain vibrational energies to agglomerated CNTs, overcoming the attractive forces within the nanomaterials and becoming dispersed within a solvent or polymeric material. Fig. 8 shows different approaches for the functionalization of CNTs.

\section{Applications of CNTs}

Nanotechnology is one of the latest and the most developed technologies, presenting many advantages and benefits for new materials with significantly improved properties. Nanotechnology can be used in different applications in various fields, including nano-medicine, energy, the environment, and in sensors [91]. Although the fields of nanotechnology are vast and new materials come into use regularly, the potential of CNTs is most promising. Since their discovery by Iijima [5] in 1991, CNTs are the most rapidly growing nanomaterials in the field of nanotechnology due to their various applications. Many investigators and researchers have dedicated much effort to the creation of novel properties and to expanding the number of novel applications in diverse fields, from materials science, medicine, electronics and energy storage, with many studies focusing on nanotechnology and the use of CNTs as fillers [92]. More attractive applications of CNTs can be achieved through the use of CNTs for applications that require conductivity and a high absorption capacity and for the creation of high-strength composites, fuel cells, ener-

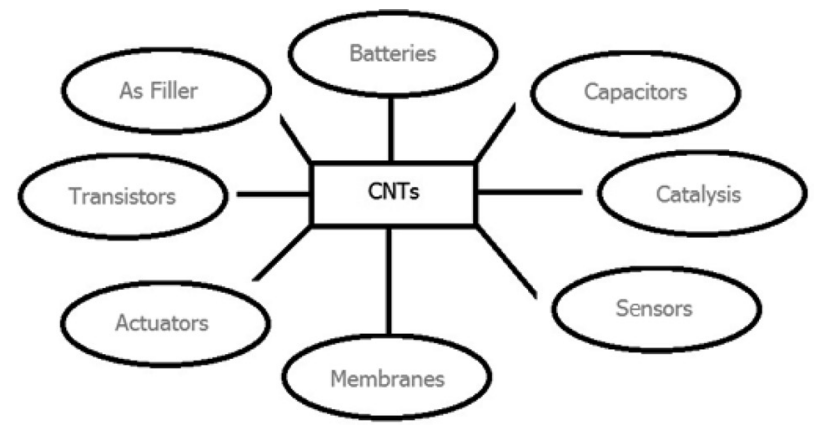

Fig. 9. Applications of CNTs.

gy conversion devices, field-emission devices, hydrogen storage devices, and semiconductor devices $[93,94]$. Wastewater treatment by CNTs is also a rapidly growing field for those who are interested in adsorption studies [95]. The major problem associated with CNTs is their high cost and nonrenewable characteristic. At present, special efforts are in progress to develop certain preparation methods for CNTs which minimize their cost. Some of the very important and promising applications of CNTs are discussed below in detail.

\subsection{CNTs as fillers}

The use of CNTs as fillers in different materials to form nanocomposites is one of the most developed fields in nanotechnology. Many researchers working in the field of nanocomposites have attempted to use CNTs as a filler. The main idea for incorporating CNTs into different polymeric and other materials is to improve the properties of these materials. By doing so, the mechanical, electrical and thermal properties are improved to almost an ideal range. Garcia-Gutierrez et al. [96] prepared Meltprocessed injected molded polybutylene terephthalate (PBT)/ SWNTs nanocomposites and presented that SWNTs effect the polymer orientation during shearing and also template the crystallization behavior of PBT. Soichia et al. [97] found that the tensile modulus and yield strength increased with an addition of SWNT loading in a SWNTs/polyimide nanocomposite. With good dispersion, they showed that the mechanical properties of polyimide were enhanced. Bhattacharyya et al. [98] prepared melt-mixed styrene maleic anhydride (SMA) encapsulated SWNTs with a polyamide-12 (PA12) matrix in a conical twin-screw extruder. The process of encapsulation by the SMA copolymer leads to a greater dispersion of SWNT and thus enhances the interfacial adhesion between the PA12 and SMAmodified SWNT. This leads to enhanced mechanical properties of the formed product. Saeed and Park [99] prepared MWNT/ nylon nanocomposites by in situ bulk polymerization. They used pristine MWNTs (P-MWNTs) and purified acid-treated MWNTs (A-MWNT) as a reinforcing material and studied the mechanical, thermal, electrical, and rheological properties as well as the structural morphology and crystallization temperature via various techniques and compared the properties of both P-MWNT/ nylon and A-PMWNT/nylon nanocomposites. It was concluded that A-MWNTs can be well dispersed in nylon as compared to P-MWNTs due to the presence of functional groups on the A-MWNTs. The crystallization temperature increased with 
an increase in the ratio of MWNTs in nylon. Prashantha et al. [100] prepared MWNTs and polypropylene (MWNT/PP) and MWNTs and polypropylene-grafted maleic anhydride (MWNT/ PP-g-MA) nanocomposites and studied the rheological, mechanical, and morphological properties of these nanocomposites with various compositions of MWNTs using a range of techniques. They reported that MWNTs have better dispersion in PP-g-MA as compared to PP, and reported that MWNTs and PP-g-MA have good adhesion and strong interfacial strength as compared to MWNTs/PP because the MWNTs/PP-g-MA have high mechanical properties and an improved rheological percolation threshold. Zhang et al. [101] fabricated poly (adipic acid-hexamethylene diamine) (PA66) and F-MWNTs. AminoMWNTs were used in the fabrication process, and the dispersion of A-MWNTs was increased in formic acid $(\mathrm{HCOOH})$ after PA66 functionalization. The PA66 materials were grafted onto the surface of A-MWNTs. It was concluded that the chain length of the PA decreased with an addition of A-MWNTs, the thermal decomposition temperature of the PA-MWNTs were higher than that of the pure PA66 composite, and the storage modulus was improved with an addition of A-MWNTs.

\subsection{In electronic devices as field-emission sources}

CNTs can be used in electric devices as field-emission sources. This can be done when a potential is applied between the CNT surface and the anode. Electrons are easily emitted from their tips due to the curvature present in the CNTs in the form of pentagons $[102,103]$ or due to the presence of oxidized tips $[104,105]$. With this principle, CNTs can be used for the fabrication of multiple electronic devices [104], including flat-panel displays, intense light sources, bright lamps [93,106,107], and X-ray sources [46,108]. Although CNTs are good emitters, nanocomposites of CNTs are also excellent electron-emission surfaces which are vacuum stable [109]. There are many advantages when using CNTs as an electron emitter. These include long lifetimes of the components, stable field-emission over prolonged time periods, low emission threshold potentials, the absence of the need for an ultra-high vacuum, and high current densities. It has been reported that large current densities as high as $4 \mathrm{~A} / \mathrm{cm}^{2}[107]$ can be achieved.

\subsection{Batteries (Lithium ions batteries)}

Lithium (Li) is a useful element, as it offers unique properties due to its lowest electronegativity and because electrons are easily donated from Li. Thus, it is the best candidate for the fabrication of lightweight and efficient batteries. However, despite the above advantages, the high reactivity of Li limits its applicability, as the metal loses its efficiency. This problem can be solved by the combining an application of CNTs and Li by intercalating $\mathrm{Li}$ ions within CNTs. This enables $\mathrm{Li}^{+}$ions to migrate from a graphitic anode to the cathode. A separating medium is required between the anode and cathode, usually polyolefin. The theoretical Li storage capacity is expected to be $372 \mathrm{mAh} / \mathrm{g}$ when intercalated with CNTs. The charge and discharge phenomena in these batteries are controlled by the $\mathrm{Li}^{+}$intercalation and de-intercalation rates $[110,111]$. Recently, Frackowiak and
Beguin [112] showed that CNTs could be used in Li ion batteries. According to these authors, a high irreversible capacity is possible for CNTs. Meunier et al. [113] carried out calculations to determine the charging and discharging phenomenon in $\mathrm{Li}^{+}$ batteries. They suggested that by damaging the surface of the SWNT materials chemically or mechanically, one can increase the electrochemical storage of these batteries. On the basis of such possibilities, many electronics companies have begun to use carbon nanofibers and nanotubes as the electrodes in $\mathrm{Li}^{+}$batteries to enhance their storage capacity and lifetimes.

\subsection{CNTs in supercapacitors and actuators}

Due to their large surface area as well as their high electrical conductivity, CNTs are excellent materials for use in electrochemical devices [107]. Niu et al. [114] and Ma et al. [115] were the first to demonstrate that with sheet electrodes of pyrolytically grown MWNTs, it is possible to achieve very high specific capacitances in individual cells in devices containing $38 \mathrm{wt} \%$ of $\mathrm{H}_{2} \mathrm{SO}_{4}$ as the electrolyte. The cells could reach power densities that exceeded 8,000 W/kg. Recently, a similar study was carried out by Frackowiak and Beguin [112] and Ma et al. [115], who demonstrated that MWNT-polypyrrole composites are able to reach specific capacitances of $163 \mathrm{~F} / \mathrm{g}$. CNT supercapacitors are used in applications to devices that require high power capabilities and higher storage capacities. The power densities approach $20 \mathrm{~kW} / \mathrm{kg}$ at energy densities of $7 \mathrm{Wh} / \mathrm{kg}$ [112]. CNT-embedded supercapacitors can be used to provide fast acceleration and to store braking energy electrically for hybrid electric vehicles. Actuators are important devices, but the problem associated with them is that their efficiency decreases with an increase in the temperature. Therefore, CNT-modified actuators were prepared by several researchers. These work at relatively low voltages and at temperatures as high as $350^{\circ} \mathrm{C}$ [116]. For example, the maximum stress observed in SWNT actuators was $26 \mathrm{MPa}$ [117]. This value is comparable to that of natural muscles, as it is 100 times larger than the value for natural muscle [103].

\subsection{Sensors}

Sensors are important detecting devices that are now widely used in different fields. The efficiency of biosensors and molecular sensors can be enhanced by attaching CNTs onto them. With chemical force microscopy techniques, Wong et al. [118] were the first to demonstrate that it is possible to sense functional chemical groups attached onto the ends of CNTs. Thus, it is possible to construct various types of sensors containing nanotube composite pellets, which are very sensitive to gases and which can be used to monitor leaks in chemical plants. Collins et al. [119] reported after working in a similar field that SWNTs are extremely sensitive to air and vacuum conditions by noting large variations in the electrical resistance levels of their SWNT samples. They also added that MWNTs can be used as efficient sensors for $\mathrm{NH}_{3}, \mathrm{H}_{2} \mathrm{O}, \mathrm{CO}_{2}$ and $\mathrm{CO}$. Varghese et al. [120] detected changes in the resistance and capacitance levels of CNTs when the environment was slightly modified. In 2002, highly sensitive and fast-responsive microwave-resonant sensors were prepared for detecting $\mathrm{NH}_{3}$ using either SWNTs or MWNTs [121]. In addition to gas sensing, CNTs and its composites can be used as 
sensitive environmental pressure sensors [122]. Wood and Wagner noted that CNTs are very sensitive to liquid immersion or polymer-embedding processes, as the nanotubes slightly deform in the presence of different liquid media [123].

\subsection{Gas and hydrogen storage}

Due to their hollow cylindrical nature, CNTs can act as efficient gas and metal containers. It has been found that many important chemical species, such as metals, metal carbides, and oxides, can be introduced into CNT core by different methods, including (a) chemical treatments, arc-discharge methods, solidstate reactions and electrochemical techniques [124]. However, the major issues pertaining to these techniques are related to the fact that CNTs are not able to encapsulate gaseous substances. Recent studies have revealed that $\mathrm{H}_{2}$ and Ar can be stored in SWNTs [125,126] and MWNTs [127], respectively. Terrones et al. [128] demonstrated experimentally that it is possible to introduce gaseous nitrogen inside MWNTs using a single-step process. They also reported that MWNTs can be loaded via the spray pyrolysis of ferrocene and benzyl amine solutions. Similar work was carried out by Trasobares et al. [129], but they used a powder pyrolysis of ferrocene and camphor under an ammonia atmosphere. The storage of different chemical species in CNTs may be advantageous for the fabrication of fuel cells for use mainly to power electric vehicles. Unfortunately, there is some controversy regarding the high-pressure storage of hydrogen. It is important to emphasize that the hydrogen storage capacity of CNTs ranges from 0.1 to $66 \mathrm{wt} \%$ [130,131]. Hirscher et al. [132] proved that the influence of impurities (coming from the CNT synthesis methods) may be responsible for reported previously results showing uptake levels as high as $7 \%$. From a theoretical point of view, density functional theory has been used to calculate the $\mathrm{H}_{2}$ storage capacity in CNTs. Different mechanisms by which CNTs possibly adsorb hydrogen molecules were proposed, including chemisorption, adsorption at interstitial sites, and the swelling of the nanotube array [133-135].

The above situations clearly show that CNTs may not be the best material for storing hydrogen, but additional experiments and further calculations should be carried out in order to clarify these results [136]. The adsorption of other gases such as He, $\mathrm{NH}_{3}, \mathrm{~N}_{2}$, and $\mathrm{SF}_{6}$ in CNTs as well as carbon foams, was recently achieved by Tanaka et al. [137].

\subsection{Scanning probe tips}

Scanning probe tips are of great importance as they can be used to obtain images with better resolutions. If a MWNT-bound scanning probe is used instead of a normal probe, it becomes possible to obtain a better image resolution as compared to earlier results [138]. Presently, Seiko Instruments and Daiken Chemical Company are attempting to commercialize these probes. Chemically modified nanotube tips can be used as sensors for detecting specific chemical and/or biological groups [125]. These sensors are important to detect added or even illegal substances. Kim and Lieber [139] determined experimentally that it is possible to fabricate nanotube tweezers by attaching two nanotubes onto a probe tip. This nano-tool operates according to the electrostatic interactions between two carbon cylinders. These achievements show clear advance regarding the use of nanotubes in current technologies, and it is clear that in the near future, further advances will be achieved.

\subsection{Electronic devices using CNTs}

CNTs are important nanomaterials that can be used in electronic devices to improve the properties of these devices. Tans et al. [38] fabricated a three-terminal switch-able device based upon SWNTs. The SWNT molecule was semiconducting and connected to metal nanoelectrodes. The performance at a low capacitance level was excellent. The major problem associated with nanotubes is the difficulty in manipulating them; thus, another method was devised to control the length and the electronic properties of individual nanotubes by STM nanostructuring [140]. Postma et al. [141] described that crossings and bends with SWNTs could be generated by means of AFM. This technique allows us to cut nanotubes into shorter sections using controlled voltages applied at the STM tips and to fabricate tiny nanotube devices that could be useful for the future construction of molecular machinery, nano-scale circuits and other nanoelectric materials [140,142]. There are many examples of experimental evidence indicating that CNTs can carry current densities of $10^{9} \mathrm{~A} / \mathrm{cm}^{2}$; these values are much lower than those observed in metals $\left(10^{5} \mathrm{~A} / \mathrm{cm}^{2}\right)$ [112]. Bachtold et al. [143] and Huang et al. [144] demonstrated for the very first time the fabrication of field-effect transistors that exhibit a high favorable gain, a large on-off ratio and room-temperature operation. The researchers showed that one-, two- and three-transistor circuits exhibit a range of digital logic operations. Examples include an inverter, a logic NOR, a static random-access memory cell, and an AC ring oscillator. A Harvard group in a similar way produced crossed nanowire $\mathrm{p}-\mathrm{n}$ junctions and junction arrays that were configured as key OR and NOR logic-gate structures, showing substantial gain. They can be used for the development of novel computer technologies in the near future. Derycke et al. [145] demonstrated that CNTs can be used as a FET. The researchers also showed that pristine CNTs always behave as p-type transistors, whereas doped-nanotubes act as n-type devices. Both types could be integrated to fabricate voltage inverters [139]. Javey et al. [146] demonstrated that it is possible to generate logic rings as well as NOR and OR logic gates using arrays of p- and n-type nanotube FETs, as it is difficult to control the chirality of the tubes with the electronic properties. Collins et al. [147] demonstrated that it is possible to peel the outer layers of arc-discharged-produced MWNTs until the desired electronic properties of the outer shell are obtained. However, controlled growth in order to achieve selective chiralities needs to be investigated and exploited for more electrical applications. Blase et al. [148] also worked with a similar hypothesis and demonstrated that the electronic properties of CNTs can be utilized within polymeric materials to realize desired electrical applications.

\subsection{Medical applications of CNTs}

Given the increased profits associated with medical technology related to gene therapy, cancer treatments, and innovative new answers for life-threatening diseases, the science of nanomedicine has become the most rapidly growing field. The 
unique properties and characteristics of CNTs enable scientists to develop new areas in nanomedicine. SWNTs and MWNTs have already proven their potential to serve as safer and effective alternatives to previous drug delivery methods. They can pass through membranes, carrying therapeutic drugs, vaccines, and nucleic acids deep into the cell to the substrate targets. They serve as ideal non-toxic vehicles, which in some cases, increase the solubility of the drug, resulting in greater efficiency and safety. Overall, recent studies of CNTs have shown a very promising future for them in medicine [149].

\section{Toxicity of CNTs and its control}

Due to the extraordinary physical and chemical properties of CNTs, their usage in industry has been seriously considered, but there are certain problems associated with their use, especially problems related to their toxicity. CNTs can have adverse effects on human health, especially at the human pulmonary system, which is a primary route of exposure [150]. This is considerable concern among researchers at present regarding this $[92,151-$ 157]. Thus, certain steps are required to minimize the toxicity of CNTs. Over-exposure to CNT dust also causes inflammation and oxidative stress [158]. A recent study of CNTs showed that the length and rigidity of the nanotubes greatly influence the proinflammatory effect of CNT [159]. However, further research is needed to determine the possible influence of other physiochemical properties [160]. As their surface characteristics influence the pro-inflammatory effect of spherical nanoparticles [161], it can be expected that incorporating CNTs in polymeric materials will modify the surface properties of CNTs, which could modify their toxicity without affecting their specific properties and potential for use in future applications. The protective effect of the compatible solute Ectoine against CNT-induced lung inflammation has been studied recently [162]. However, a strategy based on the production of intrinsically safer nanomaterials seems to offer much more promise. Such approaches are essential for the further development and safe use of CNTs at the occupational level as well as at the level of the general user. From various studies of the toxicity of CNTs, it is clear that surface modifications are important to minimize CNT toxicity [163-167]. A coating could be a useful tool, as it allows modification of the external surface environment of CNTs without affecting their intrinsic structure or basic properties.

\section{Conclusion}

The synthesis, structure, physico-chemical properties as well as different applications of CNTs were reviewed in this paper. Important methods for the synthetic of CNTs (SWNTs and MWNTs), including the arc-discharge method, laser ablation, CVD, and many other were discussed briefly. Some of the wellknown properties of CNTs were also reviewed and presented and it was concluded that CNTs have a unique set of electrical, mechanical and thermal properties. Due to the greatest potentials of CNTs, it is clear that novel technologies will emerge in the near future, but the problem associated with these technologies is the quantity and cost of CNTs. Larger quantities of nanotubes are needed if composite materials are to be fabricated. It is highly likely that low-cost gas sensors, nanotube fabrics, novel catalytic supports, three-dimensional composite materials, heat exchangers, biological microfilters, and virus inhibitors will be produced using CNTs in the future. It was also reported that the nanotube functionalization methods which disperse CNTs well lead to less toxic CNTs than pristine CNTs.

\section{References}

[1] Wagner FE, Haslbeck S, Stievano L, Calogero S, Pankhurst QA, Martinek KP. Before striking gold in gold-ruby glass. Nature, 407, 691 (2000). http://dx.doi.org/10.1038/35037661.

[2] Franks A. Nanotechnology. J Phys E, 20, 1442 (1987). http:// dx.doi.org/10.1088/0022-3735/20/12/001.

[3] Taniguchi N. On the basic concept of 'nano-technology'. Proceedings of the International Conference on Production Engineering, Tokyo, Japan, Part II (1974).

[4] Kroto HW, Heath JR, O'Brien SC, Curl RF, Smalley RE. C 60 : buckminsterfullerene. Nature, 318, 162 (1985). http://dx.doi.org/ 10.1038/318162a0.

[5] Iijima S. Helical microtubules of graphitic carbon. Nature, 354, 56 (1991). http://dx.doi.org/10.1038/354056a0.

[6] Radushkevich LV, Lukyanovich VM. O strukture ugleroda, obrazujucegosja pri termiceskom razlozenii okisi ugleroda na zeleznom kontakte (About the structure of carbon formed by thermal decomposition of carbon monoxide on iron substrate). Zurn Fisic Chim, 26, 88 (1952).

[7] Lau AKT, Hui D. The revolutionary creation of new advanced materials--carbon nanotube composites. Composites B, 33, 263 (2002). http://dx.doi.org/10.1016/S1359-8368(02)00012-4.

[8] Iijima S, Ichihashi T. Single-shell carbon nanotubes of 1-nm diameter. Nature, 363, 603 (1993). http://dx.doi.org/10.1038/363603a0.

[9] Geim AK, Novoselov KS. The rise of graphene. Nature Mater, 6, 183 (2007). http:dx.doi.org/10.1038/nmat 1849.

[10] Sheshmania S, Ashorib A, Fashapoyeha MA. Wood plastic composite using graphene nanoplatelets, Int J Biol Macromol, 58, 6 (2013). http://dx.doi.org/10.1016/j.ijbiomac.2013.03.047.

[11] Saether E, Frankland SJV, Pipes RB. Transverse mechanical properties of single walled carbon nanotube crystals. Part I: determination of elastic moduli. Compos Sci Technol, 63, 1543 (2003). http://dx.doi.org/10.1016/S0266-3538(03)00056-3.

[12] Pichler T. Molecular nanostructures: carbon ahead. Nature Mater, 6, 332 (2007). http://dx.doi.org/10.1038/nmat1898.

[13] Ajayan PM. Bulk metal and ceramics nanocomposites. In: Ajayan PM, Schadler LS, Braun PV, eds. Nanocomposite Science and Technology, Wiley-VCH Verlag GmbH \& Co., 1 (2004). http:// dx.doi.org/10.1002/3527602127.ch1.

[14] Dresselhaus MS, Lin YM, Rabin O, Jorio A, Souza AG, Pimenta MA, Saito R, Samsonidze G, Dresselhaus G. Nanowires and nanotubes. Mater Sci Engg: C, 23, 129 (2003).

[15] Prasher RS, Hu XJ, Chalopin Y, Mingo N, Lofgreen K, Volz S, Cleri F, Keblinski P. Turning carbon nanotubes from exceptional heat conductors into insulators. Phys Rev Lett, 102, 105901 (2009). http://dx.doi.org/10.1103/PhysRevLett.102.105901.

[16] Ahmad A, Kholoud MM, Abou E, Reda AA, Abdulrahman AW. Carbon nanotubes, science and technology part (I) structure, synthesis and characterization. Arabian J Chem, 5, 1 (2012). http:// 
dx.doi.org/10.1016/j.arabjc.2010.08.022.

[17] Ebbesen TW, Ajayan PM. Large-scale synthesis of carbon nanotubes. Nature, 358, 220 (1992). http://dx.doi.org/ 10.1038/358220a0.

[18] Bethune DS, Klang CH, de Vries MS, Gorman G, Savoy R, Vazquez J, Beyers R. Cobalt-catalysed growth of carbon nanotubes with single-atomic-layer walls. Nature, 363, 605 (1993). http://dx.doi.org/10.1038/363605a0.

[19] Journet C, Maser WK, Bernier P, Loiseau A, de la Chapelle ML, Lefrant S, Deniard P, Lee R, Fischer JE. Large-scale production of single-walled carbon nanotubes by the electric-arc technique. Nature, 388, 756 (1997).

[20] Thess A, Lee R, Nikolaev P, Dai H, Petit P, Robert J, Xu C, Lee YH, Kim SG, Rinzler AG, Colbert DT, Scuseria GE, Tomanek D, Fischer JE, Smalley RE. Crystalline ropes of metallic carbon nanotubes. Science, 273, 483 (1996). http://dx.doi.org/10.1126/ science.273.5274.483.

[21] Mamalis AG, Vogtländer LOG, Markopoulos A. Nanotechnology and nanostructured materials: trends in carbon nanotubes. Precis Eng, 28, 16 (2004). http://dx.doi.org/10.1016/j.precisioneng. 2002.11.002.

[22] Li WZ, Xie SS, Qian LX, Chang BH, Zou BS, Zhou WY, Zhao RA, Wang G. Large-scale synthesis of aligned carbon nanotubes. Science, 274, 1701 (1996). http://dx.doi.org/10.1126/science.274.5293.1701.

[23] Xie S, Li W, Pan Z, Chang B, Sun L. Carbon nanotube arrays. Mater Sci Eng A, 286, 11 (2000). http://dx.doi.org/10.1016/S09215093(00)00657-2.

[24] Lee CJ, Lyu SC, Kim HW, Park CY, Yang CW. Large-scale production of aligned carbon nanotubes by the vapor phase growth method. Chem Phys Lett, 359, 109 (2002). http://dx.doi. org/10.1016/S0009-2614(02)00648-6.

[25] Hahm MG, Hashim DP, Vajtai R, Ajayan PM. A review: controlled synthesis of vertically aligned carbon nanotubes. Carbon Lett, 12, 185 (2011). http://dx.doi.org/10.5714/CL.2011.12.4.185.

[26] Rao CNR, Govindaraj A, Gundiah G, Vivekchand SRC. Nanotubes and nanowires. Chem Eng Sci, 59, 4665 (2004). http:// dx.doi.org/10.1016/j.ces.2004.07.067.

[27] Ebbesen TW, Lezec HJ, Hiura H, Bennett JW, Ghaemi HF, Thio T. Electrical conductivity of individual carbon nanotubes. Nature, 382, 54 (1996). http://dx.doi.org/10.1038/382054a0.

[28] Treacy MMJ, Ebbesen TW, Gibson JM. Exceptionally high Young's modulus observed for individual carbon nanotubes. Nature, 381, 678 (1996). http://dx.doi.org/10.1038/381678a0.

[29] Chang TE, Jensen LR, Kisliuk A, Pipes RB, Pyrz R, Sokolov AP. Microscopic mechanism of reinforcement in single-wall carbon nanotube/polypropylene nanocomposite. Polymer, 46, 439 (2005). http://dx.doi.org/10.1016/j.polymer.2004.11.030.

[30] Jin FL, Park SJ. Recent advances in carbon-nanotube-based epoxy composites. Carbon Lett, 14, 1 (2013). http://dx.doi.org/10.5714/ CL.2012.14.1.001.

[31] Wepasnick KA, Smith BA, Bitter JL, Howard Fairbrother D. Chemical and structural characterization of carbon nanotube surfaces. Anal Bioanal Chem, 396, 1003 (2010). http://dx.doi. org/10.1007/s00216-009-3332-5.

[32] Chandra B, Bhattacharjee J, Purewal M, Son YW, Wu Y, Huang M, Yan H, Heinz TF, Kim P, Neaton JB, Hone J. Molecular-scale quantum dots from carbon nanotube heterojunctions. Nano Lett, 9, 1544 (2009). http://dx.doi.org/10.1021/n1803639h.
[33] Dai H, Wong EW, Lieber CM. Probing electrical transport in nanomaterials: conductivity of individual carbon nanotubes. Science, 272, 523 (1996). http://dx.doi.org/10.1126/science.272.5261.523.

[34] Choo H, Jung Y, Jeong Y, Kim HC, Ku BC. Fabrication and applications of carbon nanotube fibers. Carbon Lett, 13, 191 (2012). http://dx.doi.org/10.5714/CL.2012.13.4.191.

[35] Kim KS, Park SJ. Bridge effect of carbon nanotubes on the electrical properties of expanded graphite/poly(ethylene terephthalate) nanocomposites. Carbon Lett, 13, 51 (2012). http://dx.doi. org/10.5714/CL.2012.13.1.051.

[36] Mintmire JW, Dunlap BI, White CT. Are fullerene tubules metallic? Phys Rev Lett, 68, 631 (1992). http://dx.doi.org/10.1103/ PhysRevLett.68.631.

[37] Saito R, Fujita M, Dresselhaus G, Dresselhaus MS. Electronic structure of chiral graphene tubules. Appl Phys Lett, 60, 2204 (1992). http://dx.doi.org/10.1063/1.107080.

[38] Tans SJ, Verschueren ARM, Dekker C. Room-temperature transistor based on a single carbon nanotube. Nature, 393, 49 (1998). http://dx.doi.org/10.1038/29954.

[39] Schonenberger C, Bachtold A, Strunk C, Salvetat JP, Forro L. Interference and Interaction in multi-wall carbon nanotubes. Appl Phys A, 69, 283 (1999). http://dx.doi.org/10.1007/s003390051003.

[40] Hone J, Llaguno MC, Nemes NM, Johnson AT, Fischer JE, Walters DA, Casavant MJ, Schmidt J, Smalley RE. Electrical and thermal transport properties of magnetically aligned single wall carbon nanotube films. Appl Phys Lett, 77, 666 (2000). http:// dx.doi.org/10.1063/1.127079.

[41] Tans SJ, Devoret MH, Dai H, Thess A, Smalley RE, Geerligs LJ, Dekker C. Individual single-wall carbon nanotubes as quantum wires. Nature, 386, 474 (1997). http://dx.doi.org/ 10.1038/386474a0.

[42] Delaney P, Di Ventra M, Pantelides ST. Quantized conductance of multiwalled carbon nanotubes. Appl Phys Lett, 75, 3787 (1999). http://dx.doi.org/10.1063/1.125456.

[43] Bandaru PR, Daraio C, Jin S, Rao AM. Novel electrical switching behaviour and logic in carbon nanotube Y-junctions. Nat Mater, 4, 663 (2005). http://dx.doi.org/10.1038/nmat1450.

[44] Cheng Y, Zhou O. Electron field emission from carbon nanotubes. Comptes Rendus Physique, 4, 1021 (2003). http://dx.doi. org/10.1016/S1631-0705(03)00103-8.

[45] Modi A, Koratkar N, Lass E, Wei B, Ajayan PM. Miniaturized gas ionization sensors using carbon nanotubes. Nature, 424, 171 (2003). http://dx.doi.org/10.1038/nature01777.

[46] Yue GZ, Qiu Q, Gao B, Cheng Y, Zhang J, Shimoda H, Chang $\mathrm{S}$, Lu JP, Zhou O. Generation of continuous and pulsed diagnostic imaging $\mathrm{X}$-ray radiation using a carbon-nanotube-based fieldemission cathode. Appl Phys Lett, 81, 355 (2002). http://dx.doi. org/10.1063/1.1492305.

[47] Yu MF, Lourie O, Dyer MJ, Moloni K, Kelly TF, Ruoff RS. Strength and breaking mechanism of multiwalled carbon nanotubes under tensile load. Science, 287, 637 (2000). http://dx.doi. org/10.1126/science.287.5453.637.

[48] Ruoff RS, Tersoff J, Lorents DC, Subramoney S, Chan B. Radial deformation of carbon nanotubes by van der Waals forces. Nature, 364, 514 (1993). http://dx.doi.org/10.1038/364514a0.

[49] Palaci I, Fedrigo S, Brune H, Klinke C, Chen M, Riedo E. Radial elasticity of multiwalled carbon nanotubes. Phys Rev Lett, 94, 175502 (2005). http://dx.doi.org/10.1103/PhysRevLett.94. 175502. 
[50] Yu MF, Kowalewski T, Ruoff RS. Investigation of the radial deformability of individual carbon nanotubes under controlled indentation force. Phys Rev Lett, 85, 1456 (2000). http://dx.doi. org/10.1103/PhysRevLett.85.1456.

[51] Yang YH, Li WZ. Radial elasticity of single-walled carbon nanotube measured by atomic force microscopy. Appl Phys Lett, 98, 041901 (2011). http://dx.doi.org/10.1063/1.3546170

[52] Minary-Jolandan M, Yu MF. Reversible radial deformation up to the complete flattening of carbon nanotubes in nanoindentation. J Appl Phys, 103, 073516 (2008). http://dx.doi. org/10.1063/1.2903438.

[53] Ajayan PM, Stephan O, Colliex C, Trauth D. Aligned carbon nanotube arrays formed by cutting a polymer resin--nanotube composite. Science, 265, 1212 (1994). http://dx.doi.org/10.1126/ science.265.5176.1212.

[54] Iijima S, Brabec C, Maiti A, Bernholc J. Structural flexibility of carbon nanotubes. J Chem Phys, 104, 2089 (1996). http://dx.doi. org/10.1063/1.470966.

[55] Chopra NG, Benedict LX, Crespi VH, Cohen ML, Louie SG, Zettl A. Fully collapsed carbon nanotubes. Nature, 377, 135 (1995). http://dx.doi.org/10.1038/377135a0.

[56] Ruoff RS, Lorents DC. Mechanical and thermal properties of carbon nanotubes. Carbon, 33, 925 (1995). http://dx.doi. org/10.1016/0008-6223(95)00021-5.

[57] Dresselhaus MS, Dresselhaus G, Eklund PC. Science of Fullerenes and Carbon Nanotubes, Academic Press, San Diego, CA (1996).

[58] Overney G, Zhong W, Tomanek D. Structural rigidity and low frequency vibrational modes of long carbon tubules. Z Phys D, 27, 93 (1993). http://dx.doi.org/10.1007/BF01436769.

[59] Robertson DH, Brenner DW, Mintmire JW. Energetics of nanoscale graphitic tubules. Phys Rev B, 45, 12592 (1992). http:// dx.doi.org/10.1103/PhysRevB.45.12592.

[60] Tersoff J. Energies of fullerenes. Phys Rev B, 46, 15546 (1992). http://dx.doi.org/10.1103/PhysRevB.46.15546.

[61] Falvo MR, Clary GJ, Taylor RM 2nd, Chi V, Brooks FP Jr, Washburn S, Superfine R. Bending and buckling of carbon nanotubes under large strain. Nature, 389, 582 (1997). http://dx.doi. org/10.1038/39282.

[62] Endo M, Takeuchi K, Kobori K, Takahashi K, Kroto HW, Sarkar A. Pyrolytic carbon nanotubes from vapor-grown carbon fibers. Carbon, 33, 873 (1995). http://dx.doi.org/10.1016/00086223(95)00016-7.

[63] Zhu YQ, Sekine T, Kobayashi T, Takazawa E, Terrones M, Terrones H. Collapsing carbon nanotubes and diamond formation under shock waves. Chem Phys Lett, 287, 689 (1998). http://dx.doi. org/10.1016/S0009-2614(98)00226-7.

[64] Yu MF, Files BS, Arepalli S, Ruoff RS. Tensile loading of ropes of single wall carbon nanotubes and their mechanical properties. Phys Rev Lett, 84, 5552 (2000). http://dx.doi.org/10.1103/PhysRevLett.84.5552.

[65] Shibutani Y, Shiozaki M, Kugimiya T, Tomita Y. Irreversible deformation of carbon nanotubes under bending. J Jpn Inst Met, 63, 1262 (1999).

[66] Li F, Cheng HM, Bai S, Su G, Dresselhaus MS. Tensile strength of single-walled carbon nanotubes directly measured from their macroscopic ropes. Appl Phys Lett, 77, 3161 (2000). http://dx.doi. org/10.1063/1.1324984.

[67] Shen W, Jiang B, Han BS, Xie S. Investigation of the radial com- pression of carbon nanotubes with a scanning probe microscope. Phys Rev Lett, 84, 3634 (2000). http://dx.doi.org/10.1103/PhysRevLett.84.3634.

[68] Wang ZL, Gao RP, Poncharal P, de Heer WA, Dai ZR, Pan ZW. Mechanical and electrostatic properties of carbon nanotubes and nanowires. Mater Sci Eng C, 16, 3 (2001). http://dx.doi. org/10.1016/S0928-4931(01)00293-4.

[69] Demczyk BG, Wang YM, Cumings J, Hetman M, Han W, Zettl A, Ritchie RO. Direct mechanical measurement of the tensile strength and elastic modulus of multiwalled carbon nanotubes. Mater Sci Eng A, 334, 173 (2002). http://dx.doi.org/10.1016/ S0921-5093(01)01807-X.

[70] Sinnott SB, Shenderova OA, White CT, Brenner DW. Mechanical properties of nanotubule fibers and composites determined from theoretical calculations and simulations. Carbon, 36, 1 (1998). http://dx.doi.org/10.1016/S0008-6223(97)00144-9.

[71] Yakobson BI. Mechanical relaxation and "intramolecular plasticity" in carbon nanotubes. Appl Phys Lett, 72, 918 (1998). http:// dx.doi.org/10.1063/1.120873.

[72] Ru CQ. Effect of van der Waals forces on axial buckling of a double-walled carbon nanotube. J Appl Phys, 87, 7227 (2000). http:// dx.doi.org/10.1063/1.372973.

[73] Guanghua G, Tahir C, William AG, III. Energetics, structure, mechanical and vibrational properties of single-walled carbon nanotubes. Nanotechnology, 9, 184 (1998). http://dx.doi.org/ 10.1088/0957-4484/9/3/007.

[74] Hernandez E, Goze C, Bernier P, Rubio A. Elastic properties of C and $\mathrm{B}_{\mathrm{x}} \mathrm{C}_{\mathrm{y}} \mathrm{N}_{\mathrm{z}}$ composite nanotubes. Phys Rev Lett, 80, 4502 (1998). http://dx.doi.org/10.1103/PhysRevLett.80.4502.

[75] Ashcroft NW, Mermin ND. Solid State Physics, Harcourt Brace, Orlando, FL (1976).

[76] Kim P, Shi L, Majumdar A, McEuen PL. Thermal transport measurements of individual multiwalled nanotubes. Phys Rev Lett, 87, 215502 (2001). http://dx.doi.org/10.1103/PhysRevLett. 87.215502.

[77] Yu C, Shi L, Yao Z, Li D, Majumdar A. Thermal conductance and thermopower of an individual single-wall carbon nanotube. Nano Lett, 5, 1842 (2005). http://dx.doi.org/10.1021/n1051044e.

[78] Maultzsch J, Reich S, Thomsen C, Dobardzic E, Milosevic I, Damnjanovic M. Phonon dispersion of carbon nanotubes. Solid State Commun, 121, 471 (2002). http://dx.doi.org/10.1016/ S0038-1098(02)00025-X.

[79] Ishii H, Kobayashi N, Hirose K. Electron-phonon coupling effect on quantum transport in carbon nanotubes using time-dependent wave-packet approach. Physica E, 40, 249 (2007). http://dx.doi. org/10.1016/j.physe.2007.06.006.

[80] Maeda T, Horie C. Phonon modes in single-wall nanotubes with a small diameter. Physica B, 263-264, 479 (1999). http://dx.doi. org/10.1016/S0921-4526(98)01415-X.

[81] Kasuya A, Saito Y, Sasaki Y, Fukushima M, Maedaa T, Horie C, Nishina Y. Size dependent characteristics of single wall carbon nanotubes. Mater Sci Eng A, 217-218, 46 (1996). http://dx.doi. org/10.1016/S0921-5093(96)10357-9.

[82] Popov VN. Theoretical evidence for $T^{1 / 2}$ specific heat behavior in carbon nanotube systems. Carbon, 42, 991 (2004). http://dx.doi. org/10.1016/j.carbon.2003.12.014.

[83] Georgakilas V, Kordatos K, Prato M, Guldi DM, Holzinger M, Hirsch A. Organic functionalization of carbon nanotubes. J Am Chem Soc, 124, 760 (2002). http://dx.doi.org/10.1021/ja016954m. 
[84] Hirsch A. Functionalization of single-walled carbon nanotubes. Angew Chem Int Ed, 41, 1853 (2002). http://dx.doi.org/10.1002/ 1521-3773(20020603)41:11<1853::AID-ANIE1853>3.0.CO;2-N.

[85] Kim JH, Min BG. Functionalization of multi-walled carbon nanotube by treatment with dry ozone gas for the enhanced dispersion and adhesion in polymeric composites. Carbon Lett, 11, 298 (2010). http://dx.doi.org/10.5714/CL.2010.11.4.298.

[86] Saeed K. Review on the properties, dispersion and toxicology of carbon nanotubes. J Chem Soc Pak, 32, 561 (2010).

[87] Wu HC, Chang X, Liu L, Zhao F, Zhao Y. Chemistry of carbon nanotubes in biomedical applications. J Mater Chem, 20, 1036 (2010). http://dx.doi.org/10.1039/B911099M.

[88] Hersam MC. Progress towards monodisperse single-walled carbon nanotubes. Nat Nanotechnol, 3, 387 (2008). http://dx.doi. org/10.1038/nnano.2008.135.

[89] Wang H. Dispersing carbon nanotubes using surfactants. Curr Opin Colloid Interface Sci, 14, 364 (2009). http://dx.doi.org/ 10.1016/j.cocis.2009.06.004.

[90] Vaisman L, Wagner HD, Marom G. The role of surfactants in dispersion of carbon nanotubes. Adv Colloid Interface Sci, 128-130, 37 (2006). http://dx.doi.org/10.1016/j.cis.2006.11.007.

[91] NANOSAFE 2008. Available from: http://www.nanosafe2008. org.

[92] Helland A, Wick P, Koehler A, Schmid K, Som C. Reviewing the environmental and human health knowledge base of carbon nanotubes. Environ Health Perspect, 115, 1125 (2007). http://dx.doi. org/10.1289/ehp. 9652 .

[93] Baughman RH, Zakhidov AA, de Heer WA. Carbon nanotubes-the route toward applications. Science, 297, 787 (2002). http:// dx.doi.org/10.1126/science.1060928.

[94] Cao A, Zhu H, Zhang X, Li X, Ruan D, Xu C, Wei B, Liang J, Wu D. Hydrogen storage of dense-aligned carbon nanotubes. Chem Phys Lett, 342, 510 (2001). http://dx.doi.org/10.1016/S00092614(01)00619-4.

[95] Kar S, Bindal RC, Prabhakar S, Tewari PK, Dasgupta K, Sathiyamoorthy D. Potential of carbon nanotubes in water purification: an approach towards the development of an integrated membrane system. Int J Nucl Desalin, 3, 143 (2008). http://dx.doi. org/10.1504/IJND.2008.020221.

[96] Garcia-Gutierrez MC, Nogales A, Rueda DR, Domingo C, Garcia-Ramos JV, Broza G, Roslaniec Z, Schulte K, Davies RJ, Ezquerra TA. Templating of crystallization and shear-induced self-assembly of single-wall carbon nanotubes in a polymer-nanocomposite. Polymer, 47, 341 (2006). http://dx.doi.org/10.1016/j. polymer.2005.11.018.

[97] Siochi EJ, Working DC, Park C, Lillehei PT, Rouse JH, Topping CC, Bhattacharyya AR, Kumar S. Melt processing of SWCNTpolyimide nanocomposite fibers. Composites B, 35, 439 (2004). http://dx.doi.org/10.1016/j.compositesb.2003.09.007.

[98] Bhattacharyya AR, Potschke P, Abdel-Goad M, Fischer D. Effect of encapsulated SWNT on the mechanical properties of melt mixed PA12/SWNT composites. Chem Phys Lett, 392, 28 (2004). http://dx.doi.org/10.1016/j.cplett.2004.05.045.

[99] Saeed K, Park SY. Preparation of multiwalled carbon nanotube/ nylon-6 nanocomposites by in situ polymerization. J Appl Polym Sci, 106, 3729 (2007). http://dx.doi.org/10.1002/app.26942.

[100] Prashantha K, Soulestin J, Lacrampe MF, Claes M, Dupin G, Krawczak P. Multi-walled carbon nanotube filled polypropylene nanocomposites based on masterbatch route: improvement of dispersion and mechanical properties through PP-g-MA addition. Express Polym Lett, 2, 735 (2008). http://dx.doi.org/10.3144/expresspolymlett.2008.87.

[101] Zhang XX, Meng QJ, Wang XC, Bai SH. Poly(adipic acid-hexamethylene diamine)-functionalized multi-walled carbon nanotube nanocomposites. J Mater Sci, 46, 923 (2011). http://dx.doi. org/10.1007/s10853-010-4836-2.

[102] De Vita A, Charlier JC, Blase X, Car R. Electronic structure at carbon nanotube tips. Appl Phys A, 68, 283 (1999). http://dx.doi. org/10.1007/s003390050889.

[103] Bonard JM, Stockli T, Maier F, de Heer WA, Chatelain A, Salvetat JP, Forro L. Field-emission-induced luminescence from carbon nanotubes. Phys Rev Lett, 81, 1441 (1998). http://dx.doi. org/10.1103/PhysRevLett.81.1441.

[104] Rinzler AG, Hafner JH, Nikolaev P, Nordlander P, Colbert DT, Smalley RE, Lou L, Kim SG, Tomanek D. Unraveling nanotubes: field emission from an atomic wire. Science, 269, 1550 (1995). http://dx.doi.org/10.1126/science.269.5230.1550.

[105] Saito Y, Hamaguchi K, Hata K, Uchida K, Tasaka Y, Ikazaki F, Yumura M, Kasuya A, Nishina Y. Conical beams from open nanotubes. Nature, 389, 554 (1997). http://dx.doi.org/10.1038/39221.

[106] Saito Y, Uemura S, Hamaguchi K. Cathode ray tube lighting elements with carbon nanotube field emitters. Jpn J Appl Phys, 37, L346 (1998). http://dx.doi.org/10.1143/JJAP.37.L346.

[107] Rotman D. The nanotube computer. MIT Technol Rev, 105, 36 (2002). http://www.technologyreview.com/featuredstory/401378/ the-nanotube-computer/.

[108] Sugie H, Tanemura M, Filip V, Iwata K, Takahashi K, Okuyama F. Carbon nanotubes as electron source in an X-ray tube. Appl Phys Lett, 78, 2578 (2001). http://dx.doi.org/10.1063/1.1367278.

[109] Xia H, Wang Y, Lin J, Lu L. Hydrothermal synthesis of $\mathrm{MnO}_{2} /$ CNT nanocomposite with a CNT core/porous $\mathrm{MnO}_{2}$ sheath hierarchy architecture for supercapacitors. Nanoscale Res Lett, 7, 33 (2012). http://dx.doi.org/10.1186/1556-276X-7-33.

[110] Evanoff K, Benson J, Schauer M, Kovalenko I, Lashmore D, Ready WJ, Yushin G. Ultra strong silicon-coated carbon nanotube nonwoven fabric as a multifunctional lithium-ion battery anode. ACS Nano, 6, 9837 (2012). http://dx.doi.org/10.1021/nn303393p.

[111] Lee NS, Chung DS, Han IT, Kang JH, Choi YS, Kim HY, Park SH, Jin YW, Yi WK, Yun MJ, Jung JE, Lee CJ, You JH, Jo SH, Lee CG, Kim JM. Application of carbon nanotubes to field emission displays. Diamond Relat Mater, 10, 265 (2001). http://dx.doi. org/10.1016/S0925-9635(00)00478-7.

[112] Frackowiak E, Beguin F. Electrochemical storage of energy in carbon nanotubes and nanostructured carbons. Carbon, 40, 1775 (2002). http://dx.doi.org/10.1016/S0008-6223(02)00045-3.

[113] Meunier V, Kephart J, Roland C, Bernholc J. Ab initio investigations of lithium diffusion in carbon nanotube systems. Phys Rev Lett, 88, 075506 (2002). http://dx.doi.org/10.1103/PhysRevLett.88.075506.

[114] Niu C, Sichel EK, Hoch R, Moy D, Tennent H. High power electrochemical capacitors based on carbon nanotube electrodes. Appl Phys Lett, 70, 1480 (1997). http://dx.doi.org/10.1063/1.118568.

[115] Ma RZ, Liang J, Wei BQ, Zhang B, Xu CL, Wu DH. Processing and performance of electric double-layer capacitors with blocktype carbon nanotube electrodes. Bull Chem Soc Jpn, 72, 2563 (1999).

[116] Jurewicz K, Delpeux S, Bertagna V, Beguin F, Frackowiak E. Supercapacitors from nanotubes/polypyrrole composites. Chem 
Phys Lett, 347, 36 (2001). http://dx.doi.org/10.1016/S00092614(01)01037-5.

[117] Baughman RH, Cui C, Zakhidov AA, Iqbal Z, Barisci JN, Spinks GM, Wallace GG, Mazzoldi A, De Rossi D, Rinzler AG, Jaschinski O, Roth S, Kertesz M. Carbon nanotube actuators. Science, 284, 1340 (1999). http://dx.doi.org/10.1126/science.284.5418.1340.

[118] Wong SS, Joselevich E, Woolley AT, Cheung CL, Lieber CM. Covalently functionalized nanotubes as nanometre- sized probes in chemistry and biology. Nature, 394, 52 (1998). http://dx.doi. org/10.1038/27873.

[119] Collins PG, Bradley K, Ishigami M, Zettl A. Extreme oxygen sensitivity of electronic properties of carbon nanotubes. Science, 287, 1801 (2000). http://dx.doi.org/10.1126/science.287.5459.1801.

[120] Varghese OK, Kichambre PD, Gong D, Ong KG, Dickey EC, Grimes CA. Gas sensing characteristics of multi-wall carbon nanotubes. Sens Actuators B, 81, 32 (2001). http://dx.doi. org/10.1016/S0925-4005(01)00923-6.

[121] Chopra S, Pham A, Gaillard J, Parker A, Rao AM. Carbon-nanotube-based resonant-circuit sensor for ammonia. Appl Phys Lett, 80, 4632 (2002). http://dx.doi.org/10.1063/1.1486481.

[122] Wood JR, Wagner HD. Single-wall carbon nanotubes as molecular pressure sensors. Appl Phys Lett, 76, 2883 (2000). http:// dx.doi.org/10.1063/1.126505.

[123] Wood JR, Zhao Q, Frogley MD, Meurs ER, Prins AD, Peijs T, Dunstan DJ, Wagner HD. Carbon nanotubes: from molecular to macroscopic sensors. Phys Rev B, 62, 7571 (2000). http://dx.doi. org/10.1103/PhysRevB.62.7571.

[124] Banhart F, Grobert N, Terrones M, Charlier JC, Ajayan PM. Metal atoms in carbon nanotubes and related nanoparticles. Int J Mod Phys B, 15, 4037 (2001). http://dx.doi.org/10.1142/ S0217979201007944.

[125] Park SJ, Lee SY. Hydrogen storage behaviors of carbon nanotubes/metal-organic frameworks-5 hybrid composites. Carbon Lett, 10, 19 (2009). http://dx.doi.org/10.5714/CL.2009.10.1.019.

[126] Liu C, Fan YY, Liu M, Cong HT, Cheng HM, Dresselhaus MS. Hydrogen storage in single-walled carbon nanotubes at room temperature. Science, 286, 1127 (1999). http://dx.doi.org/10.1126/science.286.5442.1127.

[127] Gadd GE, Blackford M, Moricca S, Webb N, Evans PJ, Smith AM, Jacobsen G, Leung S, Day A, Hua Q. The world's smallest gas cylinders? Science, 277, 933 (1997). http://dx.doi.org/10.1126/ science.277.5328.933.

[128] Terrones M, Kamalakaran R, Seeger T, Ruhle M. Novel nanoscale gas containers: encapsulation of $\mathrm{N}_{2}$ in $\mathrm{CN}_{\mathrm{x}}$ nanotubes. Chem Commun, (23), 2335 (2000). http://dx.doi.org/10.1039/B008253H.

[129] Trasobares S, Stephan O, Colliex C, Hug G, Hsu WK, Kroto HW, Walton DRM. Electron beam puncturing of carbon nanotube containers for release of stored $\mathrm{N}_{2}$ gas. Eur Phys J B, 22, 117 (2001). http://dx.doi.org/10.1007/BF01322353.

[130] Chambers A, Park C, Baker RTK, Rodriguez NM. Hydrogen storage in graphite nanofibers. J Phys Chem B, 102, 4253 (1998). http://dx.doi.org/10.1021/jp9801141.

[131] Chen P, Wu X, Lin J, Tan KL. High $\mathrm{H}_{2}$ uptake by alkali-doped carbon nanotubes under ambient pressure and moderate temperatures. Science, 285, 91 (1999). http://dx.doi.org/10.1126/science.285.5424.91.

[132] Hirscher M, Becher M, Haluska M, Quintel A, Skakalova V, Choi YM, Dettlaff-Weglikowska U, Roth S, Stepanek I, Bernier P, Leonhardt A, Fink J. Hydrogen storage in carbon nanostructures. J
Alloys Compd, 330-332, 654 (2002). http://dx.doi.org/10.1016/ S0925-8388(01)01643-7.

[133] Gordon PA, Saeger RB. Molecular modeling of adsorptive energy storage: hydrogen storage in single-walled carbon nanotubes. Ind Eng Chem Res, 38, 4647 (1999). http://dx.doi.org/10.1021/ ie990503h.

[134] Meregalli V, Parrinello M. Review of theoretical calculations of hydrogen storage in carbon-based materials. Appl Phys A, 72, 143 (2001). http://dx.doi.org/10.1007/s003390100789.

[135] Lee SM, An KH, Lee YH, Seifert G, Frauenheim T. A hydrogen storage mechanism in single-walled carbon nanotubes. J Am Chem Soc, 123, 5059 (2001). http://dx.doi.org/10.1021/ ja003751+.

[136] Darkrim FL, Malbrunot P, Tartaglia GP. Review of hydrogen storage by adsorption in carbon nanotubes. Int J Hydrogen Energy, 27, 193 (2002). http://dx.doi.org/10.1016/S0360-3199(01)00103-3.

[137] Tanaka H, El-Merraoui M, Steele WA, Kaneko K. Methane adsorption on single-walled carbon nanotube: a density functional theory model. Chem Phys Lett, 352, 334 (2002). http://dx.doi. org/10.1016/S0009-2614(01)01486-5.

[138] Dai H, Hafner JH, Rinzler AG, Colbert DT, Smalley RE. Nanotubes as nanoprobes in scanning probe microscopy. Nature, 384, 147 (1996). http://dx.doi.org/10.1038/384147a0.

[139] Kim P, Lieber CM. Nanotube nanotweezers. Science, 286, 2148 (1999). http://dx.doi.org/10.1126/science.286.5447.2148.

[140] Venema LC, Wildoer JWG, Tuinstra HLJT, Dekker C, Rinzler AG, Smalley RE. Length control of individual carbon nanotubes by nanostructuring with a scanning tunneling microscope. Appl Phys Lett, 71, 2629 (1997). http://dx.doi.org/10.1063/1.120161.

[141] Postma HWC, de Jonge M, Yao Z, Dekker C. Electrical transport through carbon nanotube junctions created by mechanical manipulation. Phys Rev B, 62, R10653 (2000). http://dx.doi. org/10.1103/PhysRevB.62.R10653.

[142] Park JY, Yaish Y, Brink M, Rosenblatt S, McEuen PL. Electrical cutting and nicking of carbon nanotubes using an atomic force microscope. Appl Phys Lett, 80, 4446 (2002). http://dx.doi. org/10.1063/1.1485126.

[143] Bachtold A, Hadley P, Nakanishi T, Dekker C. Logic circuits with carbon nanotube transistors. Science, 294, 1317 (2001). http:// dx.doi.org/10.1126/science.1065824.

[144] Huang Y, Duan X, Cui Y, Lauhon LJ, Kim KH, Lieber CM. Logic gates and computation from assembled nanowire building blocks. Science, 294, 1313 (2001). http://dx.doi.org/10.1126/science. 1066192.

[145] Derycke V, Martel R, Appenzeller J, Avouris P. Carbon nanotube inter- and intramolecular logic gates. Nano Lett, 1, 453 (2001). http://dx.doi.org/10.1021/n1015606f.

[146] Javey A, Wang Q, Ural A, Li YM, Dai HJ. Carbon Nanotube Transistor Arrays for Multistage Complementary Logic and Ring Oscillators. Nano Lett, 2, 929 (2002).

[147] Collins PG, Arnold MS, Avouris P. Engineering carbon nanotubes and nanotube circuits using electrical breakdown. Science, 292, 706 (2001). http://dx.doi.org/10.1126/science.1058782.

[148] Blase X, Charlier JC, De Vita A, Car R, Redlich P, Terrones M, Hsu WK, Terrones H, Carroll DL, Ajayan PM. Boron-mediated growth of long helicity-selected carbon nanotubes. Phys Rev Lett, 83, 5078 (1999). http://dx.doi.org/10.1103/PhysRevLett.83.5078.

[149] Akiladevi D, Basak S. Carbon nanotubes (CNTs) production, characterization and its applications. Int J Adv Pharm Sci, 1, 187 
(2010). http://dx.doi.org/10.5138/ijaps.2010.0976.1055.01024.

[150] Satishkumar BC, Govindaraj A, Nath M, Rao CNR. Synthesis of metal oxide nanorods using carbon nanotubes as templates. J Mater Chem, 10, 2115 (2000). http://dx.doi.org/10.1039/B002868L.

[151] Choi YM, Lee DS, Czerw R, Chiu PW, Grobert N, Terrones M, Reyes-Reyes M, Terrones H, Charlier JC, Ajayan PM, Roth S, Carroll DL, Park YW. Nonlinear behavior in the thermopower of doped carbon nanotubes due to strong, localized states. Nano Lett, 3, 839 (2003). http://dx.doi.org/10.1021/n1034161n.

[152] Simeonova PP. Update on carbon nanotube toxicity. Nanomedicine, 4, 373 (2009). http://dx.doi.org/10.2217/nnm.09.25.

[153] Shvedova AA, Kagan VE, Fadeel B. Close encounters of the small kind: adverse effects of man-made materials interfacing with the nano-cosmos of biological systems. Annu Rev Pharmacol Toxicol, 50, 63 (2010). http://dx.doi.org/10.1146/annurev.pharmtox.010909.105819.

[154] Oberdorster G. Safety assessment for nanotechnology and nanomedicine: concepts of nanotoxicology. J Intern Med, 267, 89 (2010). http://dx.doi.org/10.1111/j.1365-2796.2009.02187.x.

[155] Warheit DB, Sayes CM, Reed KL, Swain KA. Health effects related to nanoparticle exposures: environmental, health and safety considerations for assessing hazards and risks. Pharmacol Ther, 120, 35 (2008). http://dx.doi.org/10.1016/j.pharmthera.2008.07.001.

[156] Li Z, Hulderman T, Salmen R, Chapman R, Leonard SS, Young SH, Shvedova A, Luster MI, Simeonova PP. Cardiovascular effects of pulmonary exposure to single-wall carbon nanotubes. Environ Health Perspect, 115, 377 (2007). http://dx.doi.org/10.1289/ ehp.9688.

[157] Nemmar A, Hoylaerts MF, Hoet PH, Dinsdale D, Smith T, Xu $\mathrm{H}$, Vermylen J, Nemery B. Ultrafine particles affect experimental thrombosis in an in vivo hamster model. Am J Respir Crit Care Med, 166, 998 (2002). http://dx.doi.org/10.1164/rccm.200110026OC.

[158] Nemmar A, Vanbilloen H, Hoylaerts MF, Hoet PH, Verbruggen A, Nemery B. Passage of intratracheally instilled ultrafine particles from the lung into the systemic circulation in hamster. Am J Respir Crit Care Med, 164, 1665 (2001). http://dx.doi. org/10.1164/ajrccm.164.9.2101036.

[159] Poland CA, Duffin R, Kinloch I, Maynard A, Wallace WA, Seaton
A, Stone V, Brown S, Macnee W, Donaldson K. Carbon nanotubes introduced into the abdominal cavity of mice show asbestos-like pathogenicity in a pilot study. Nat Nanotechnol, 3, 423 (2008). http://dx.doi.org/10.1038/nnano.2008.111.

[160] Lam CW, James JT, McCluskey R, Arepalli S, Hunter RL. A review of carbon nanotube toxicity and assessment of potential occupational and environmental health risks. Crit Rev Toxicol, 36, 189 (2006). http://dx.doi.org/10.1080/10408440600570233.

[161] Stern ST, McNeil SE. Nanotechnology safety concerns revisited. Toxicol Sci, 101, 4 (2008). http://dx.doi.org/10.1093/toxsci/ kfm169.

[162] Sydlik U, Gallitz I, Albrecht C, Abel J, Krutmann J, Unfried $\mathrm{K}$. The compatible solute ectoine protects against nanoparticleinduced neutrophilic lung inflammation. Am J Respir Crit Care Med, 180, 29 (2009). http://dx.doi.org/10.1164/rccm.200812$19110 \mathrm{C}$.

[163] Fenoglio I, Greco G, Tomatis M, Muller J, Raymundo-Pinero E, Beguin F, Fonseca A, Nagy JB, Lison D, Fubini B. Structural defects play a major role in the acute lung toxicity of multiwall carbon nanotubes: physicochemical aspects. Chem Res Toxicol, 21, 1690 (2008). http://dx.doi.org/10.1021/tx800100s.

[164] Johnston HJ, Hutchison GR, Christensen FM, Peters S, Hankin S, Aschberger K, Stone V. A critical review of the biological mechanisms underlying the in vivo and in vitro toxicity of carbon nanotubes: the contribution of physico-chemical characteristics. Nanotoxicology, 4, 207 (2010). http://dx.doi. org/10.3109/17435390903569639.

[165] Kayat J, Gajbhiye V, Tekade RK, Jain NK. Pulmonary toxicity of carbon nanotubes: a systematic report. Nanomedicine, 7, 40 (2011). http://dx.doi.org/10.1016/j.nano.2010.06.008.

[166] Tong H, McGee JK, Saxena RK, Kodavanti UP, Devlin RB, Gilmour MI. Influence of acid functionalization on the cardiopulmonary toxicity of carbon nanotubes and carbon black particles in mice. Toxicol Appl Pharmacol, 239, 224 (2009). http://dx.doi. org/10.1016/j.taap.2009.05.019.

[167] Vittorio O, Raffa V, Cuschieri A. Influence of purity and surface oxidation on cytotoxicity of multiwalled carbon nanotubes with human neuroblastoma cells. Nanomedicine, 5, 424 (2009). http:// dx.doi.org/10.1016/j.nano.2009.02.006. 